\title{
INFRAESTRUTURAS POROSAS: vivendo através do consumo no Programa Minha Casa Minha Vida ${ }^{1}$
}

\author{
POROUS INFRASTRUCTURES: \\ living through consumption in Brazil's public housing program
}

Moisés Kopper*

\begin{abstract}
Resumo
No Brasil e sua economia política da mobilidade, a casa tornou-se uma infraestrutura experimental através da qual cidadania e consumo se sobrepõem na performação de um Estado democrático e promotor de inclusão social e econômica. Este artigo baseia-se em pesquisa etnográfica conduzida entre 2012 e 2015 em um condomínio fechado na cidade de Porto Alegre/RS, parte do Programa Minha Casa Minha Vida, a maior política habitacional brasileira. Economistas, sociólogos e antropólogos chamaram a atenção para a "financeirização" dos pobres, suas "vidas interconectadas", suas "economias de compartilhamento", e seu "capital moral", chegando mesmo a desenvolver novas metodologias como "diários financeiros" para entender suas realidades cotidianas. Aqui, dou continuidade a esta literatura ao mergulhar nos trabalhos e expectativas de pessoas concretas, na medida em que se deslocam de assentamentos informais para ambientes urbanos de classe média. Nessa economia da esperança, a plasticidade de vida coalesce com uma economia do crédito para deslanchar novos projetos subjetivos e coletivos, tornados visíveis por meio de suas práticas financeiras. $\mathrm{O}$ artigo destrincha essa economia política da casa própria através de três topografias - de mercado, da autonomia, do progresso - mostrando como a casa tornou-se o nódulo articulador de políticas participativas e economias de consumo que reconfiguram o espaço do político na vida econômica.
\end{abstract}

Palavras-Chave: Consumo. Política pública. Materialidade. Infraestrutura.

\begin{abstract}
In Brazil's post-neoliberal government of upward mobility and public policies, infrastructures are the symbiosis of experimental forms of government, political action, and practices of consumption. This article draws from ethnographic research conducted between 2012 and 2015 in one condominium of the Minha Casa Minha Vida policy-Brazil's largest public housing program. Economists, sociologists and anthropologists have called attention to the "financialization" of the poor; their "interconnected" lives; their "economies of sharing"; and their "moral capital", even developing new methodologies such as "financial diaries" to grasp their ordinary realities. Here, I draw from this body of literature to delve into people's travails and expectations as they move from peri-urban illegal settlements to middle-class urban environments. In this economy of hope, I argue, people's plasticity of life coalesces with a booming credit economy to unleash new personal projects and collective becomings, rendered visible when coping with money. The article unravels the political economy of the house by exploring three topographies-market, autonomy, progress-and interrogating the house as the binding figure of participatory governance and consumption-led economies, thus reconfiguring the site of the political in economic life.
\end{abstract}

Keywords: Consumption. Public policy. Materiality. Infrastructure.

1 Uma versão modificada deste artigo foi apresentada no $18^{\circ}$ Congresso Brasileiro de Sociologia, Brasília, 2017, no Grupo de Trabalho "Sociologia Econômica - Pluralismo de enfoques e inovação metodológica". O projeto de pesquisa que serve de base ao artigo contou com o apoio da Fapesp, sob processo nº. 2016/16265-1.

* Doutor em antropologia social pela Universidade Federal do Rio Grande do Sul/Brasil. Atualmente, realiza pós-doutorado junto ao Max-Planck-Institute for the Study of Societies/Alemanha. E-mail: moiseskopper@gmail.com. 


\section{Introdução}

Em 2012, o Coeficiente de Gini, indicador clássico de mensuração da desigualdade de renda, caiu para o menor patamar desde 1960 (PAES DE BARROS, FOGUEL, AND ULYSSEA, 2007). Políticas públicas setoriais desempenharam papel preponderante na trajetória de redução das desigualdades de renda no Brasil (ARRETCHE, 2015). Com a estabilidade inflacionária do Plano Real, o aumento real do salário mínimo, a expansão do crédito e dos programas de transferência condicionada de renda, economistas, jornalistas, políticos e marqueteiros celebraram a ascensão econômica de milhões de brasileiros e seu descolamento da pobreza em direção a uma "nova classe média", definida na releitura de estatísticas nacionais e tornada alvo de intervenções governamentais e de mercado (NERI, 2008; SALATA, 2016; SOUSA and LAMOUNIER, 2010; SOUZA, 2010; XAVIER SOBRINHO, 2011).

Como demonstrei em outras oportunidades (KOPPER, 2014, 2015A, 2016A, p.1-2; 2016B; KOPPER and DAMO, 2018), a gramática da "nova classe média" constituiu a linguagem hegemônica a partir da qual se discutiu os avanços e percalços da mobilidade ascendente na década de 2000. Críticos dessa tese apontaram para as limitações do conceito de classe puramente baseado em renda e distinções econômicas, argumentando por uma noção inspirada em preceitos marxistas (BARTELT, 2013; CHAUÍ, 2013; POCHMANN, 2012, 2014) e weberianos (SALATA, 2013; 2016; SCALON, 2011; SCALON and SALATA, 2012; SOUZA, 2010) de classe.

Neste artigo, não estou interessado na genealogia das controvérsias científicas e intervenções difusas realizadas em nome desta suposta nova classe econômica. Antes, argumento que as transformações socioeconômicas dos últimos quinze anos produziram uma população de beneficiários-consumidores, cuja mobilidade ascendente esteve associada à implantação de políticas redistributivas (FERGUSON, 2015), e que traz novos elementos para repensar a ideia de classe e mobilidade no Brasil. Sugiro que entender as subjetividades políticas e econômicas emergentes nesses arranjos é fundamental para auferir os rumos de políticas públicas, seus impactos de longo prazo, e os coletivos ambivalentes que florescem em meio às novas experiências de classe e de estratificação.

A pesquisa etnográfica que serve de aporte a esta análise foi conduzida entre 2012 e 2015 em um condomínio fechado na cidade de Porto Alegre/RS, parte do Programa Minha Casa Minha Vida, a maior política habitacional brasileira². Estruturado em torno da concessão de um bem específico - a casa própria e os objetos que a povoam -, o horizonte da mobilidade ascendente propiciado pelo acesso à política habitacional aponta para a presença ubíqua de infraestruturas como vetores de desejos. Artefatos são, aqui, menos veículos semióticos

\footnotetext{
2 A pesquisa empírica incluiu a realização de observação participante de longo prazo junto a beneficiários de um complexo modelo construído em Porto Alegre, pontuada por entrevistas com beneficiários, executores locais da política, agentes de mercado e de estado, comerciantes e arquitetos. A pesquisa também incluiu a realização de um survey sociodemográfico com 160 famílias em 2015 e 2017 com o propósito de traçar as mudanças e continuidades nas disposições políticas e econômicas desses beneficiários no tempo.
} 
da cultura, que materialidades porosas através das quais devires circulam, são agenciados, e ganham vida. Por meio da política e da poética das infraestruturas (LARKIN, 2013), é possível documentar e cartografar os sentidos de classe in-the-making. Artefatos são fundamentais, ainda, para compreender como dinâmicas políticas e econômicas de governo se encontram e informam a gestação de devires subjetivos e coletivos. De modo particular no caso de políticas habitacionais, a casa-sua simbologia, imaginário, construção, apropriação e consumofaz convergir esses diferentes registros e realidades em contínuas operações de valorização e tradução (VATIN, 2013).

No Brasil recente da mobilidade e das políticas públicas, a relação simbiótica entre os fluxos de coisas e os devires das pessoas depende da participação destas na sociedade de consumo e na economia do crédito. Em junho de 2013, o governo federal lançou o Programa Minha Casa Melhor, uma linha de crédito pré-aprovada de $\mathrm{R} \$ 5$ mil, concedida a juros reduzidos de $5 \%$ ao ano, que estabelece categorias de bens de consumo e valores máximos afixados para a compra de eletrodomésticos e móveis para os novos apartamentos (ver tabela 1) 3 $^{3}$ Como veremos, muitas pessoas utilizaram-se desse instrumento de crédito no custeio das despesas da mudança e o acoplaram a outras formas de pagamento, negociando e tergiversando seus limites financeiros na busca por autonomia, escolha e progresso.

Economistas, sociólogos e antropólogos chamaram a atenção para a "financeirização" dos pobres (MÜLLER, 2014), suas "vidas interconectadas" (ZELIZER, 2011), suas "economias de compartilhamento" (YACCOUB, 2015), e seu "capital moral" (WILKIS, 2013), chegando mesmo a desenvolver novas metodologias como "diários financeiros" (COLLINS, et al. 2009; MORDUCH and SCHNEIDER, 2017; OSSANDÓN, et al. 2017) para entender suas realidades cotidianas. Aqui, dou continuidade a esta literatura ao mergulhar nos trabalhos e expectativas de pessoas concretas, na medida em que refazem suas vidas domésticas através do acesso ao consumo. Uma arqueologia das práticas e instrumentos financeiros de gestão do espaço e seus materiais permite visibilizar os padrões de relações que atravessam a casa e a configuram como o epicentro de uma temporalidade da esperança. Nesse processo, busco ainda restituir a dimensão política e de governo subjacente a esses instrumentos, em geral pouco debatida nesses estudos.

Como escreveu Clara Han (2011), as relações cotidianas das pessoas com os novos objetos adquiridos pelo boom dos instrumentos de crédito materializam disputas sobre os horizontes do possível, visto como o indeterminado das relações vividas no presente. O consumo torna-se, portanto, uma balança entre a demarcação de status e distinção (BOURDIEU, 1984; LIVINGSTON, 2009) e a performação de "gestures of care" e "[affective] relations in the hope of rendering something new in them" (HAN, 2011. p.9). Traçar o movimento, a saturação, a porosidade e os registros financeiros dessas infraestruturas habitacionais, ajuda a entender

3 O Programa durou cerca de um ano e meio e foi interrompido no início de 2015, devido à falta de recursos para custear os financiamentos. Até ali, o governo contabilizou R \$ 2,92 bilhões em empréstimos-muito abaixo da previsão inicial, de R \$ 18,7 bilhões-, para 640mil famílias. De início, o governo havia repassado R\$ 8 bi para a CEF, dos quais R 5 bi para custos administrativos e capitalização do banco e R 3 bi para financiamentos. 
as redes mais amplas de dependências - vizinhos (novos e antigos), lideranças comunitárias, instrumentos de crédito e de policymaking - em meio às quais devires humanos, espaciais e materiais são orquestrados.

O artigo está dividido em três seções empíricas e um comentário analítico que serve de conclusão. As primeiras acompanham os caminhos da aquisição, fluxo e transformação de materiais associados à casa própria em três cenas etnográficas, aqui chamadas de topografias. Ao apropriar-me de um conceito tradicionalmente empregado pela geografia, busco recuperar a simbiose espacial e material em meio às quais práticas de governo e instrumentos de mercado coalescem e dão forma a experiências de transformação subjetiva (FERGUSON, 2004; WEIGEL, 2009). Circulando pelos espaços íntimos e públicos dessa amálgama, mostro, nessas seções, como aspirações, imaginários de classe média, dignidade e respeitabilidade são incrustados na arquitetura dos apartamentos através da apropriação e consumo desses artefatos.

$\mathrm{Na}$ última parte, analiso algumas das implicações teóricas dessas topografias, ilustrando como esses beneficiários costuraram uma terceira via para o dilema da voz (política) e da saída (mercado) discutido por Hirschman (1970) ao construírem espaços público-privados de consumo, autonomia e escolha que refazem o papel do político na vida econômica. Por meio da inclusão na sociedade de consumo, novas ansiedades e expectativas de classe são desenhadas em torno do crédito e da temporalidade aspiracional da dívida (MURPHY, 2014). Materialidades tornam-se, assim, nexo processuais, malhas porosas e janelas empíricas para explorar realidades políticas, econômicas, interpessoais e afetivas em fluxo.

\section{Topografias de Mercado}

Em agosto de 2014, inúmeras famílias beneficiárias do Programa Minha Casa Minha Vida correram para uma das maiores lojas de eletrodomésticos do Brasil. Militantes pela casa própria, elas haviam se organizado em 2009 para fundar o Conselho de Desenvolvimento do Partenon (CODESPA), uma associação que pressionou a prefeitura para comprar uma área de terras no bairro Partenon, em Porto Alegre, e ali construir 540 unidades habitacionais. Graças às conexões político-partidárias do movimento e à participação assídua de centenas de famílias nessas reuniões mensais, o projeto vingou e, em setembro de 2014, 160 delas puderam mudar-se para o recém-inaugurado Residencial Bento Gonçalves. Semanas antes da mudança, Seu Ilmo Silva, gerente daquele estabelecimento, fora até uma das reuniões da associação para falar do cartão Minha Casa Melhor e propor uma parceria: abriria sua loja, após o expediente regular, exclusivamente para os membros do movimento.

Em todo o Brasil, empresas de varejo passaram a se interessar em vender seus produtos e serviços para as "classes populares" brasileiras, as maiores beneficiadas com as recentes políticas de aumento da renda e de mobilidade econômica (KOPPER, 2015b). Para potencializar sua entrada nesse universo e recriar as fronteiras desse mercado, recorreram aos institutos de pesquisa 
de mercado que, desde 2001, se especializaram na "nova classe média" brasileira. Em 2012, por exemplo, a Movelsul Brasil - maior feira de exposição de móveis da América Latina, realizada anualmente na cidade de Bento Gonçalves - passou a usar um serviço de consultoria de mercado com o objetivo de redirecionar seu escopo para esse segmento da população. Segundo Vanessa Machado, coordenadora de marketing com quem conversei em abril de 2014, a pesquisa foi levada a cabo pelo Instituto Data Popular e explorou o comportamento do consumidor brasileiro no que se refere à compra de móveis. "Em 2013, as empresas de móveis populares foram as que mais cresceram no setor, enquanto que as fabricantes de planejados enfrentaram dificuldades para não fechar o ano no vermelho", completou. A feira, que gera volume anual de R\$ 1 bilhão em negócios nacionais e internacionais, consolidou um modelo de negócios operacionalizado por grandes magazines como as lojas de seu Ilmo e por consumidores populares que, segundo a pesquisa teria apontado, enfatizam a decoração com tons claros, mobília moderna e móveis pré-moldados.

"Essas pessoas precisam aprender a administrar o dinheiro. Precisam aprender a consumir, e nós estamos aqui para ajudar, entendemos que esse é um projeto social", começou Seu Ilmo, gerente da loja onde muitos membros do CODESPA compraram seus móveis, em conversa pessoal, alguns dias depois. Ao longo dos últimos dois anos, Silva viu vários clientes oriundos do PMCMV chegarem à sua loja. Baseando-se nessas experiências, ele entendia que as pessoas deveriam aprender a ajustar seus desejos e expectativas aos orçamentos domésticos e às condições e limites físicos de suas novas unidades.

Em sua perspectiva, os beneficiários da casa própria haviam recebido uma oportunidade única para repensar suas vidas através das novas condições materiais deflagradas pela política pública. A compra de objetos, associada à possibilidade de decorar autonomamente um espaço doravante próprio, seria condutora de uma plasticidade material alinhavada aos travails das pessoas em construir um novo self. Tratava-se de um passo crucial no exercício controlado da cidadania. Através de inclusão econômica, o uncanny transfigurar-se-ia no homely; o objetivo último de Bachelard (1958), a casa como topografia do selfe do íntimo, seria finalmente realizado através da marquetização e configuração de um lar adequado, educando pessoas sobre como viver renovadamente para além da pobreza.

"Nós sempre tivemos interesse em atender a esse público", Silva continuou. "É claro que alguns planos, como esse [PMCMV] que o governo lançou no mercado trazem um volume maior de vendas". Ao oferecer diferentes linhas de produtos-com variados padrões de acabamento, cores, formatos e linhas-e dispô-los lado a lado, Silva desencadeava um não-planejado efeito aspiracional em seu público. Na elaboração de seu mix de produtos, Silva estava preocupado em manter uma linha de baixo custo, que atendia investidores visando construir empreendimentos para o que chamou de "classe popular". "Eu vejo que há uma preocupação saudável do governo, que é fazer a pessoa querer vislumbrar um produto acima das condições financeiras. Automaticamente, depois disso ele vai mobiliar essa casa, ele vai ter um produto condizente 
com aquele padrão". Para Silva, era preciso estar atento às novas circunstâncias de consumo propiciadas pela democratização do acesso à bens e tecnologia nessa faixa de renda, a TV não seria mais de tubo, e a máquina de lavar ter-se-ia tornado uma das prioridades no orçamento doméstico. Seu Ilmo instruía, então, seus vendedores a ensinarem uma visão holista da casa própria aos novos consumidores:

\begin{abstract}
Nós precisamos clarificar a importância de ter um ambiente doméstico mais confortável. Ao invés da pessoa chegar aqui e dizer: 'ah, eu quero a maior televisão de 50 polegadas que tu tem; não, quem sabe tu não compra uma TV menor, de 32 polegadas, que vai te dar a possibilidade de gastar o resto do crédito em um beliche pra acomodar os filhos, por exemplo. As pessoas sabem que tem um limite de crédito pra cada item, mas ainda assim elas vêm aqui e me perguntam, 'posso pagar a diferença?'. Claro que eu ia adorar vender uma máquina de lavar de $\mathrm{R} \$ 2500$, mas eu não posso. O limite que o governo estipulou é $\mathrm{R} \$ 1000$ ! O que a gente tenta é fazer a pessoa imaginar o ambiente da cozinha: tu vai ter uma pia, tu vai ter uma mesa prum jantar em família, tu vai ter uma sala com um sofá. Mas não dá para colocar um sofá de sete lugares; tem que ser um de dois, talvez mais uma poltrona.
\end{abstract}

Ao colocar os cidadãos-consumidores no radar econômico da política habitacional, seu Ilmo os ensinava a como fazer uso apropriado do dinheiro-que se tornou um operador para pedagogizar a entrada em uma nova vida, pontuada por novas responsabilidades, prioridades, deveres e direitos. Através dessas práticas, Seu Ilmo operava como um designer ativo de casas e sujeitos, performando-os, isto é, "casando" e "subjetificando" os microcosmos que ele ajudava a construir. Seu trabalho não cessava com a venda de bens; ao contrário, estendia-se até a própria imaginação do ambiente doméstico e os modos considerados adequados para sua ocupação. Nesse processo, seu papel assemelhava-se ao de outras figuras envolvidas na produção de desiring citizens, como líderes comunitários, autoridades municipais, ou mesmo assistentes sociais, todos engajados em entregar "dignidade e inclusão aos pobres". "Eu fiquei sensibilizado desde o primeiro dia que eu vi a organização do CODESPA na batalha por um futuro melhor", revelou naquela conversa. Apesar disso, seu raciocínio estava profundamente amarrado numa linguagem econômica, já que a construção de um lar demandaria que as pessoas retornassem continuamente à sua loja para a compra de outros bens e obtenção de novos créditos além daquele concedido pelo cartão Minha Casa Melhor.

Enquanto falava de suas experiências ordinárias com beneficiários do PMCMV, Ilmo fez diversas referências aos critérios de corte por categoria de bem de consumo da política de crédito (ver tabela a seguir). Os limites financeiros estipulados pelas diretrizes do programa Minha Casa Melhor operavam, na prática, em colaboração com as fronteiras morais de pessoas como Dona Maria. Naquela mesma noite de sábado de 2014, enquanto escolhia seus móveis na loja de Seu Ilmo, ela revelou: "Eu quero coisa simples. Não sou rica, se eu fosse rica eu me esbaldava”. Em seu conjunto, as categorias de bens criadas pelo instrumento de crédito reproduziam conceitos que orientavam indicadores macroeconômicos em pesquisas de domicílios, como a PNAD e o 
Critério Brasil. Ao adquirir produtos em cada uma dessas categorias, os consumidores poderiam ter a certeza de que haviam sido incluídos na sociedade de consumo por meio da criação de um lar adequado à família nuclear da unidade doméstica. Ao replicar, em uma linguagem monetária, as divisões e hierarquias morais que converteram desiring citizens em alvos de intervenções habitacionais, o programa Minha Casa Melhor traduzia uma pedagogia de consumo embebida no design dos instrumentos de crédito e materializada na voz de gerentes de loja como Seu Ilmo.

Tabela 1 - Itens do Programa Minha Casa Melhor por Faixa de Preço

\begin{tabular}{lr}
\hline ITEM & PREÇO MÁXIMO \\
& DE VENDA \\
\hline Guarda-Roupa & Até R\$700 \\
Cama de casal/beliche, com ou sem colchão, ou cama box de casal & Até R\$500 \\
Cama de solteiro/berço com selo INMETRO, com ou sem colchão, ou cama box de solteiro & Até R\$400 \\
Mesa com cadeiras & Até R\$400 \\
Sofá & Até R\$600 \\
Estante ou rack & Até R $\$ 350$ \\
Móveis para cozinha & Até R\$600 \\
Refrigerador & Até R\$1090 \\
Fogão & Até R\$599 \\
Micro-ondas & Até R\$350 \\
Lavadora de Roupas Automática & Até R\$1100 \\
TV Digital & Até R\$1400 \\
Computador ou notebook, com capacidade de acesso à internet & Até R\$1150 \\
Tablet, tela igual ou superior a 7", 8GB, câmera, wifi, cartão SD & Até R\$800 \\
\hline
\end{tabular}

Fonte: Caixa Econômica Federal. Esquematização: Autor

"Pegamos duas televisões, um sofá, um computador pro nosso filho, uma cama de casal pra nós, dois colchões de solteiro pra eles, o fogãozinho e o computador", comentou o casal branco, de meia idade, Moacir e Melissa, enquanto terminavam de negociar o valor de seus bens na mesa de Seu Ilmo. "Nós fizemos um acerto com o gerente, ele foi bem acessível, aí fechou tudo, deu R\$ 4.969", a esposa seguiu. "Nada foi jogado", ela continuou, referindo-se à prática de flexibilizar os limites estipulados através de arranjos em que eram discriminados apenas parte dos valores pagos pelos bens. "Só a TV que nós pegamos duas e passou do limite, mas colocaram em outra nota fiscal e ficou tranquilo. O sonho dos guris é ter TV no quarto; agora ta realizado".

O casal vinha planejando a aquisição de móveis segundo as diretrizes do cartão Minha Casa Melhor há muito tempo. "A prioridade eram os meninos", Melissa estabeleceu. Para ela, a aquisição do computador significava a porta de entrada para a internet, para a ampliação dos estudos e para a construção da privacidade dos filhos. Um deles lhe prometera que ensinaria a mãe a "mexer" no laptop. "Quinze anos de aluguel. Quinze anos de luta. Correndo de uma casa pra outra, sendo despejado, nós sofremos, passamos fome. E hoje eu tenho o meu canto". Moacir trabalhava de vigilante e Melissa fazia as vezes de doméstica para complementar a renda do 
casal. "Agora quem sabe eu não preciso mais trabalhar de domingo a domingo".

Em meio ao desejo de erguer a família da pobreza, tiveram o auxílio dos pais, que doaram presentes para a nova casa e estavam até mais felizes que eles, disse Moacir. "Infelizmente", Melissa deu sequência, "não estão aqui para nos ver entrar": a mãe falecera há três meses e o pai agonizava com câncer terminal. "O sonho dela era ver nós no apartamento. Mas ela ta com nós, ela vai acompanhar a nossa entrada", ela lamentou aos prantos. "Minha filha", dissera-lhe o pai em leito de morte, "eu tô chegando ao fim, mas eu não morro até ver tu entrar no teu apartamento".

Sorrindo, Moacir recapitulou a sucessão de fatos, esperanças perdidas e reanimadas, lutas e reuniões que marcaram os últimos cinco anos em que se tornara um militante pela casa própria: "Todos os dias da semana, do mês, a gente olhava aquele papelzinho da inscrição. De mudança em mudança se perdia móvel, se perdia isso, mas o papel tava lá, 'esse é o meu número, ta chegando aí! Vai chegar!', completou. Para os filhos, um dos quais sofria de epilepsia e precisava de cuidado médico constante, Melissa ensinou a importância de guardar dinheiro e ser agradecido por todos os benefícios:

O meu filho chorava, o pequeno, o de dez anos que tava junto, 'mãe, nós vamos conseguir?'. E eu brincando com ele pra ele saber que o dinheiro não vem de qualquer lata, não vem de qualquer coisa. Eu disse 'filho, se nós não vamos ser sorteados, não vai ter apartamento. Aí eu chorava e disse, 'viu por que às vezes a mãe pede filho, vamos economizar, vamos tentar trocar uma bolachinha por uma bolacha mais saudável, não só a bolachinha, vamos comer um pão, tudo poupar pra ter condições... E ele quer correr o mundo, ele quer fazer aula de inglês...

Melissa esperava arduamente ter sua humanidade restituída. Via na abertura de desejos dos filhos uma porta para reencontrar-se consigo própria. A aquisição da casa simbolizava essa caminhada de longo prazo que temperava suas expectativas e mantinha seus desejos vivos. "Meu sonho, acima de tudo, é ver os meus filhos se dando bem... O meu desejo, pessoalmente, é voltar a estudar, que eu larguei os estudos por falta de dinheiro. Tomara que o apartamento traga isso de volta", ela concluiu com o olhar longe.

Insatisfeitas com os limites por categoria de bem impostos pelo Minha Casa Melhor, outras pessoas passaram a procurar Seu Ilmo para negociarem canais alternativos de aquisição de objetos de maior valor. “Isso aqui é um absurdo! Não da pra comprar nada com esse dinheiro!", uma senhora negra com semblante fechado vociferou em direção aos racks com preços proibitivos que se enfileiravam um do lado da outro. A exceção era o menor e mais frágil deles, rejeitado pela senhora: "Querem empurrar isso goela abaixo porque somos pobres", queixou-se. Ela se sentiu lesada em seu direito à livre escolha no espaço do mercado, possibilitado pela política de inclusão econômica que a convertera em uma cidadã com voz. Como marcadores de status, os objetos eram desenhados para performar limites de classe em uma sociedade pontuada por amplas desigualdades socioeconômicas (KOPPER, 2014; 2015a). Como condutores de mobilidade, a 
compra de eletrodomésticos e móveis de qualidade superior ao limite estipulado pelo governo sinalizava a busca das pessoas por produtos de maior durabilidade (que as demarcavam como consumidores conscientes) e o desejo por ascensão econômica - simultaneamente instigado e freado pelo Estado ao converter as "classes populares" em consumidores.

Nesses casos, Seu Ilmo buscava inicialmente reafirmar os critérios da CEF, embora na prática oferecesse possibilidades que combinavam múltiplas fontes de crédito: o cartão do governo, cartões de crédito de bancos e a própria linha de crédito comercializada pela loja. Como as tentativas das pessoas em "pagar a diferença" mostravam, a gramática moral e econômica do beneficiário colocava em jogo uma miríade de modalidades de dinheiro, cruzadas durante a negociação de bens e opções de pagamento. O cartão de crédito instrumentado pelo governo operava como um meio relacional de troca, muitas vezes percebido como um dom, um presente, um benefício, ou uma graça: exatamente porque suas parcelas mensais diminutas e espraiadas em 48 prestações permitiam que o empréstimo fosse despercebido como tal no cotidiano.

Como Viviana Zelizer convincentemente mostrou quanto ao earmarked money (1994), economias domésticas funcionam desencadeando circuitos de comércio dentro do capitalismo (ZELIZER, 2005a), conectando agentes através do fluxo de dinheiro, da produção social e do significado e troca de bens. A cadeia de consumo da casa coloca no centro dos debates os complexos entrelaçamentos entre intimidade e economia (ZELIZER, 2005b) que florescem na textura do trabalho relacional das pessoas (ZELIZER, 2011), num processo constante de habitar o mundo. Em linha com sua obra, argumento que, como crédito que emerge do governo, o cartão Minha Casa Melhor esteve sujeito a diversas apropriações e marcações de sentido que enfatizaram a autonomia das pessoas como consumidoras da casa. Nesse processo, como veremos na próxima seção, elas colocaram em marcha imagens da casa e do ambiente doméstico, usando conjuntos específicos de transações e comprando tipos particulares de bens. Ao empregá-los no cotidiano de suas novas vidas, esses objetos se tornaram materialidades políticas, isto é, instrumentos que, adquiridos na circulação e interação com o crédito governamental, narram histórias individuais e coletivas de mobilidade e de sucesso.

\section{Topografias da Autonomia}

Dia 4 de outubro [de 2014], um dia antes das eleições. Correria. Não trouxe quase nada, era muito úmido e não deu pra aproveitar muita coisa. Trouxe geladeira, cama e guarda-roupa, máquina de lavar e minha cama, e esses sofás. O resto estragou tudo. Era muito saco. Saco de roupa, era caixa com coisas da cozinha. Era um terror. No domingo de manhã quando eu acordei, olhei, não reconheci o lugar. Meu Deus, onde que eu to? Abri a porta. Vim pra sala. Me sentei. Fiquei olhando. Ah, Meu Deus, eu não acredito. Aí caiu a ficha que eu não ia precisar fazer o que eu fazia lá onde eu morava quando chovia. Era um Deus nos acuda. Não acredito, sem goteira, sem correria, é meu! Tava vazio, tinha pouca coisa, mas pra mim era lindo, mesmo vazio. Sei que ainda tem dez anos pela frente pra que realmente seja meu. Mas to pagando direitinho, tenho a certeza de que é meu. Daqui eu não saio daqui ninguém me tira [risos]. 
Delci sempre morou em Porto Alegre. Aos 19 anos, quando casou, mudou-se para perto do asfalto, na Avenida Ipiranga, retornando em seguida ao Morro da Cruz, onde permaneceu por 17 anos, em um terreno da família. Casada e com dois filhos, ela encontrava-se desempregada na época de nossa conversa, em janeiro de 2015. Delci participou da maior parte das reuniões do CODESPA, desde a realização do primeiro seminário "Do Morro para o Asfalto", em 2009. Antes disso, frequentou por cinco anos uma associação de luta pela moradia que, como disse, "não deu em nada". "Eu não vi na liderança aquela coisa de vai dar certo, vamos se unir, organizar, as coisas eram perdidas, não tinha reunião, teu nome não tava na lista", comentou, sugerindo que eram essas diferenças na arquitetura da participação que mantiveram sua esperança acesa na militância. Por várias vezes, Delci fez planos de comprar uma casa, mas esbarrava nas complicações financeiras decorrentes do aluguel e do desemprego. "Não sobra dinheiro pra comprar, não sobra". Como outras mulheres do condomínio, ela via no apartamento o ponto de chegada de uma caminhada que passava pela busca incessante da casa própria e pela construção de um legado para as gerações vindouras: "Vocês não sabem o quanto eu to feliz. É o sonho de uma vida. Me casei de 19 pra 20, to com 40, não pensava que eu ia conseguir ter algo meu, a gente não vai viver a vida inteira e eu queria ter algo pra deixar pros meus filhos", desabafou.

Para mobiliar a casa nova, Delci utilizou o cartão do governo, o Minha Casa Melhor, e comprou os móveis na loja de Seu Ilmo, através da parceria do CODESPA. Antes disso, teve um problema de cadastro na CEF, comum a outras pessoas com as quais conversei; ela teve de se deslocar até uma agência bancária para que o crédito fosse liberado em cerca de dez dias úteis. "Não usei todo o limite. Comprei o que eu necessitava. Uma dívida é uma dívida", sentenciou. Desde a infância, Delci considerou-se como o polo racional de sua família: "Comigo sempre é na ponta do lápis, eu sempre tomei as rédeas de tudo, desde que morava com a mãe", explicou.

“Tu tem a prestação da casa, água, luz, despesas de comida, roupa... Quando eu vim eu achei que seria menos despesa, mas sabia que poderia correr esse risco", continuou Delci. Em seu planejamento doméstico, ela havia encontrado um meio de calcular os gastos e planejar os investimentos no apartamento. "Isso influenciou no modo como a gente administra o dinheiro", confessou a dona de casa, que já tratava de acomodar a nova despesa, o pagamento do IPTU. "Eu penso em comprar algo, mas eu não posso porque vai vir essa conta, senão não vai dar. Quando o meu marido recebe eu já tiro o dinheiro da prestação, do condomínio, da água e da luz, o resto eu tiro depois. Antes não era assim porque não tinha condomínio e prestação", arrematou.

Delci comprou rack e televisão para a sala, mesa com cadeiras para a cozinha e mobiliou o quarto do filho. Ela tomara a decisão de privilegiar o filho - que precisava de um computador - dispensando, naquele momento, a compra de uma secadora de roupas. "É um adolescente, eles querem ter as coisas deles", argumentou, enquanto demonstrava como esses bens serviam para a construção da individualidade do rapaz, que agora tinha seu quarto próprio. Quem a convenceu de que precisava comprar objetos para o apartamento todo fora seu marido. "R\$ 120 fixos não é uma prestação alta, ele decidiu comprar o que a gente precisa”, sugeriu. 
Uma das questões centrais no processo de mudança de endereço, o aumento das despesas financeiras decorrentes da transferência deixou de se afigurar como um problema. "Agora é água no meu nome, luz no meu nome, tudo no meu nome! Agora eu tenho comprovante de renda!", os olhos arregalados brilhavam. "Antes era gato, nada se pagava. Dá pra levar, mas é muito mais gasto", completou. Ela procedeu a um cálculo de sua nova agenda de pagamentos: a) prestação da Caixa Econômica, R \$ 25; b) taxa de condomínio, R \$ 143; c) taxa social de água, $R$ \$ 19; d) taxa social de luz, em torno de R\$25; e) prestação do cartão Minha Casa Melhor, R\$ 120. Ao todo, a nova conta somava cerca de $\mathrm{R} \$ 335$, que Delci aceitava pagar sem titubear. "É como se antes a gente não existia! Onde tu mora? Eu moro naquele beco ali. Até para buscar emprego, eles te veem com outros olhos", exclamou.

Apesar das melhorias, Delci foi rápida em afirmar que nem tudo mudou. Ela seguia levando seus filhos para o antigo colégio e consultava no mesmo posto de saúde. Em sua crítica pragmática do PMCMV, a mudança de endereço incitou, sobretudo, uma transformação subjetiva, mas não resolveu os problemas de infraestrutura que não eram previstos pela política pública. "Falta uma creche, falta um posto de saúde, falta infraestrutura. Agora vai superlotar os daqui que vem todo mundo pra cá", raciocinou. Em compensação, o acesso a supermercados e a transporte público estava mais fácil.

Apesar da alegria em planejar o espaço doméstico, Delci não ficou satisfeita com a qualidade dos móveis recebidos. "A bancada da cozinha eu fui abrir e saí com a porta na mão. O guarda-roupas do meu filho tu abria uma gaveta e não abria a outra”. Ela atribuiu esses problemas a falhas na montagem, razão pela qual entrou em contato, por telefone, com a loja de Seu Ilmo, relatando o inconveniente. "Eles vão aí, a senhora não sai daí. Uma hora vão chegar na tua casa", teriam lhe dito. Três semanas haviam se passado e nenhum montador aparecera. Delci permaneceu dias no apartamento até que finalmente decidiu conversar pessoalmente com Seu Ilmo, na loja. "Foi aí que as coisas aconteceram", concluiu.

Delci também teve problemas com a qualidade do apartamento. Alguns dias após a mudança, uma chuva de grandes proporções criou poças de água no chão de um dos quartos. Ela entrou em contato com a construtora, que demorou um mês, entre idas e vindas, para resolver a situação. "Sou dura na queda, insisti bastante. Quando vão resolver? Não interessa como, eu to pagando, é meu dever, eu to cumprindo. Também tenho o direito de cobrar, porque se eu não pagar vão me cobrar, não vão? Então também tenho que cobrar", teria dito aos técnicos da empresa. Uma vez o problema do vazamento resolvido, começara o seguinte: choques nas janelas, resolvido em dois dias. Finalmente, o piso passou a apresentar rachaduras e soltou em certos pontos do quarto. Delci deixou novo papel no setor de acompanhamento da construtora e aguardou contato. "Ninguém apareceu. Os rapazes vieram ver o piso e disseram que não podiam fazer nada. Que essa parte tinha sido finalizada pela outra construtora, que a Caixa tinha que autorizar. Disseram pra entregar outro papelzinho. Eu digo, outro?”. De modo geral, Delci avaliou que a cobrança era problemática e abordada pelos técnicos da CEF 
e da construtora "na defensiva". "Fiquei sabendo que tem o 0800, o serviço de qualidade. Liguei e falei tudo que tinha acontecido. Eles queriam trocar só a parte estragada e iriam me deixar com pisos de cores diferentes. Não aceitei. Deveria ter mais agilidade, tudo é muito complicado", queixou-se.

Delci, entretanto, seguia tecendo projetos para apropriar-se da casa e convertê-la no projeto sonhado, em meio às tratativas com a empresa na busca por fazer valer seus recém descobertos direitos como cidadã-consumidora. "Ainda quero comprar um sofá novo, pintar a sala, algumas coisas que dá pra fazer. Nada que mexa com a estrutura que ta ótima, mas algo que deixe a minha cara, uma cortina diferente nos quartos, os boxes do banheiro, nada de mais", declarou. Quando pedi que deixasse uma mensagem final para um futuro documentário, não teve dúvidas: "Pra gente é um resgate da dignidade. Tu sabe que tem um lugar pra tu ir, que não é insalubre, é limpo, seguro, bom pra te criar teus filhos. É o sonho da maioria dos brasileiros. Chega uma hora que tu fala, meu Deus pra onde eu vou? Eu vou deixar esse apartamento pros meus bebês", confessou. Pela primeira vez, Delci considerava-se entre os afortunados brasileiros a ter sua casa própria, passando da imaginação do sonho à imaginação da realidade.

\section{Topografias do Progresso}

Perto dali residia Ana Paula, uma mulher negra, de meia idade, que há muito tempo atrás, ainda no início dos anos 1990, residira em apartamento. O imóvel fora comprado com o dinheiro do seguro de vida de seu pai, ex-funcionário da extinta CRT [Companhia Rio-Grandense de Telecomunicações]. "Fiz um mau negócio", ela comentou, "eu tinha um contrato de gaveta que a Caixa não reconhecia. Perdi o apartamento, só não fiquei na rua porque eu retornei à casa da minha mãe pro meu quarto de solteira, com uma filha de 19 anos". Sua mãe morava na Vila São José, no bairro Partenon. Por longos anos, Ana Paula pensou em realizar investimentos na casa, mas não tinha espaço para guardar seus pertences. Juntou algum dinheiro enquanto aguardava a certeza de que, através do CODESPA, o sonho da casa própria se materializaria. Em 2010, porém, com a festa de 15 anos da filha, o pouco dinheiro economizado foi consumado no evento.

Ana Paula sempre trabalhou como telefonista em call centers, incluindo-se finais de semana e feriados. "É horrível. Foi assim que eu criei minha filha, que sempre estudou em escola particular. Foi tudo dividido entre eu e o pai dela", prosseguiu com a narrativa. Enquanto acompanhava e batalhava pelo desenvolvimento da filha, Ana Paula buscou informações para aprimorar sua própria educação; primeiramente, sobre um curso de recursos humanos na Ulbra. "Sempre fui fascinada, mas era impossível de pagar. Não tinha EAD, não tinha dinheiro, sem perspectiva nenhuma de vida, nada na minha vida acontecia. Eu saía de um call center pra outro e pagava o colégio da minha filha", confessou. "Quando eu tiver oportunidade vou fazer esse curso. Vamos pensar no progresso", ela teria dito para si mesma. 
Em 2010, a chance de iniciar um curso de graduação em recursos humanos à distância, na Unilaselva, concretizou-se. Ana Paula tinha aulas presenciais a cada segunda-feira e formouse alguns anos mais tarde. "Hoje a graduação é um ensino médio", ela então raciocinara. "Vou fazer uma pós. Fiquei entre psicologia organizacional e gestão de pessoas com ênfase em couch, que é o que eu faço. Eu pensei: a psicologia ta voltada da porta da empresa pra dentro, já a gestão é um mercado que tu faz toda hora". As dificuldades, entretanto, se assomaram e em janeiro de 2015 Ana Paula já considerava trancar o curso, devido à falta de oportunidades de estágio na área para pessoas sem experiência profissional. Aliado a isso, Ana Paula estava desempregada e pretendia recomeçar em outro call center. "Vou retroceder pra buscar no curto prazo, mas meu currículo está em todo lugar", sugeriu.

A situação de incertezas econômicas influenciou sua opinião sobre a nova vida no residencial Bento Gonçalves. "Sou muito ativa, não me atiro, sempre penso no amanhã. Fiquei muito depressiva, tinha tardes que eu passava num choro só, horrível, por estar em casa sem perspectiva. Ninguém te liga, nem para dizer que é engano", comentou em tom de desabafo. Sua filha estava iniciando o curso de graduação em psicologia enquanto tratava de arrumar espaço para o primeiro emprego de recepcionista. "Esse mês é ela quem vai pagar as contas", revelou. Em sua narrativa, Ana Paula constatava um descompasso entre sua qualificação curricular e a alta rotatividade em empregos subdimensionados, que aceitava para dar conta das despesas no residencial. "Quando me mudei, estava sem dinheiro, sem renda mensal. Foi bom, eu tava feliz, mas foi frustrante. Eu queria fazer outras coisas, pintar essa parede. Isso tornou-se supérfluo porque entre fazer o mercado e a parede tu vai fazer um mercado", constatou. Apesar disso, todas as suas contas, à exceção do IPTU, estavam em dia.

As dificuldades financeiras não impediram que Ana Paula usasse o cartão Minha Casa Melhor para a aquisição de novos pertences para o apartamento. Com ele, comprou um sofá, uma televisão e um rack para a sala; um micro-ondas e móveis para a cozinha; uma cama para a filha, roupeiro, colchão e um jogo de armários, além de uma máquina de lavar roupas. Da casa antiga, trouxe apenas um roupeiro, uma mesa com cadeiras, uma cômoda e um livreiro. De sua mãe, ganhou de presente uma geladeira, comprada pela internet, e um fogão usado.

Em sua experiência com diferentes lojas, ela constatou diferenças de tratamento por conta da utilização do cartão. "As pessoas já te olham não muito bem, acham que tu é totalmente miserável, que tu é leiga, não tem estudo nenhum, não te respeitam, te discriminam", queixouse. Em uma delas, Ana Paula foi deparada com uma planilha de objetos e custos, que chamou de "cesta básica de eletrodomésticos e móveis" (ver p. 7). "É um xerox dos xerox da Caixa. Até concordo que tem que ter uma ordem porque a gente sabe que tem pessoas lunáticas. Mas o que eu desejei e almejei eu comprei", afirmou. Um dos principais bens procurados por Ana Paula foi a máquina de lavar roupas. Primeiramente, foi até as lojas CR Mentz, onde lhe ofereceram "marcas inferiores" e olharam-na como "pobre e favelada, que desceu do morro e ta no asfalto". Ela disse que queria levar uma Brastemp ou Eletrolux: "eu conheço o que é bom, não sou uma 
pessoa ignorante que não sou informada". "Nesse cartão não passa", disseram-lhe. "Então eu não vou levar. Atravessei a rua, fui no Magazine Luiza, fui muito bem atendida e comprei a marca que eu queria", arrematou.

Enquanto terminava de formatar e criar seu ambiente doméstico - planejando a colocação de grades e a compra de utensílios como porta-sabonetes -, Ana Paula seguia à procura de um emprego na sua área de formação, para poder usufruir plenamente dos benefícios da nova residência. "A gente tem que pensar no progresso, na vida. Vou me tornar uma gestora de RH", esbravejou com o olhar cintilante. Para ela, um sentido de imanência e de valor moral à vida era forjado à medida que tecia projetos futuros que alinhavam sua realização profissional à construção de um sentido de continuidade intergeracional, um legado que seria passado à filha: "Quero deixar esse apartamento para a minha filha, minha única herdeira. Não penso em vender, mas em dez anos posso alugar, fazer renda. Minha filha pode morar aqui, ou eu fico e ela sai, ela tem a sua autonomia. É isso que eu penso", concluiu.

\section{Considerações Finais: vozes críticas e coletivos transientes}

Em Exit, Voice and Loyalty (1970), o economista e pensador político Albert Hirschman analisa as estratégias antagônicas através das quais atores sociais respondem a situações adversas e procuram exercer influência. Ele estabelece uma distinção entre saída, que envolve remover-se totalmente de uma situação, e voz, que implica mudar a situação a partir de dentro por meio de críticas e demandas. Enquanto a saída segue dinâmicas de mercado convencionais, voz é, em suas palavras, ação política por excelência, já que sinaliza a adoção de táticas que deslocam os pilares de uma dada configuração. Lealdade, por sua vez, seria o mecanismo que regula o uso de voz ou saída; quanto mais forte a lealdade, maior a preocupação do indivíduo pelo bem-estar coletivo para além de sua própria participação e, portanto, maiores as chances de eficácia da voz sobre a saída.

Entre os beneficiários da casa própria que encontrei em Porto Alegre, tornar-se parte da sociedade de consumo via acesso a política habitacional significava, antes de tudo, construir um canal de transformação do sujeito. Materializada numa temporalidade da espera e do endividamento, a sinergia das pessoas com os artefatos revelava a casa, sua decoração e administração, como o site político, econômico e social, por excelência, para a recriação do self e o governo da vida social. Nos processos de uso e apropriação da arquitetura, novos devires, em estado bruto, eram lapidados, expandindo as fronteiras de imaginação de futuros e das chances em vida.

As camadas sociotécnicas formadas pelo consumo de objetos, instrumentos de crédito e artes de existência, sedimentaram novos horizontes - imbricados - do econômico e do político, complicando a caracterização de Hirschman. $\mathrm{Na}$ interação de escalas que produz a nova vida em condomínio - pontuada por pagamentos de financiamentos e taxas, convivências coletivas e 
projetos de ascensão social - um excedente simbólico foi produzido: a autonomia como escolha. É nesse espaço construído - e coletivamente sancionado - que a passagem para a casa própria e o consumo de seus objetos se consolidou. Vista como o resultado de uma escolha que envolve sacrifícios concretos e diários, a mudança foi justificada pelos ganhos de propriedade e autonomia na transformação dos objetos que passaram a povoar os novos ambientes da vida privada. $\mathrm{O}$ consumo e propriedade desses bens tornou-se, então, a base sobre a qual transformações, usos criativos, cuidado e manutenção coalesceram, expondo a transformação do próprio sujeito. Como um permanente work in progress, a casa se torna um nexo processual, uma malha porosa e uma janela empírica para explorar realidades políticas, econômicas, interpessoais e afetivas em fluxo.

Através do consumo, os beneficiários da casa própria esculpiram novos alicerces para o exercício de sua própria voz. Reconfigurado no interior de projetos de mobilidade ascendente, o apartamento seguidamente é apresentado como um legado intergeracional e um ativo de instanciação do futuro, em que novos sentidos de propriedade e herança aparecem associados à experiência de classe. Aqui, a voz como ativo político é exercida em instâncias materiais que possibilitam o controle, planejamento e execução do futuro, revelando que o projeto de mobilidade se desdobra em uma espiral que busca abarcar também gerações vindouras. O apartamento torna-se, assim, o locus para a educação dos filhos e a organização da vida financeira. Quartos individualizados e computadores garantem que o direito à voz nunca seja esquecido. Como um lugar de imaginação e prospecção, o apartamento permite também recalibrar as aspirações em direção a empregos melhores e projetos de educação.

O campo de autonomia e escolha aberto pelo consumo na esfera individual dos apartamentos e suas materialidades cristaliza-se, ainda, na invenção de figuras híbridas, legais e coletivas, de cidadãos-consumidores. Insatisfações quanto aos limites impostos pelo cartão de crédito governamental, à qualidade construtiva dos apartamentos, das opções e materiais empregados nos móveis, do atendimento de lojas, encontraram canais para sua visibilização crítica através de subjetividades em busca de seus direitos e devires. Através da temporalidade controlada do consumo e acesso a bens e serviços, essas pessoas forjaram canais para o exercício de sua cidadania e pertencimento econômico. Buscando caminhos para a respeitabilidade, para um senso de normalidade e para o reconhecimento social de suas transformações subjetivas por meio do mercado, elas deslocaram e realinharam os espaços de politização da vida social, recombinando suas vozes críticas em coletivos transientes e refazendo, no processo, as fronteiras da lealdade.

Nesse processo, suas vozes engendraram alguma sorte de accountability política e econômica, que era também o substrato de uma transformação subjetiva, e o fundamento de uma busca constante pelo lugar e estatuto do privado nas novas configurações abertas pela política pública e suas instâncias de mercado. Ao atravessarem as unidades domésticas (que são, também, unidades de governo), os devires, sonhos e expectativas críticas encapsulados nas materialidades 
transientes dos objetos de consumo encontraram sua base de lealdade no coletivo imaginado do condomínio. Como uma realidade em permanente disputa e construção, entretanto, essa lealdade efêmera era tencionada pela busca do lugar do individual e do progresso, conferindo às pessoas o poder para o exercício de uma cidadania econômica com alguma influência nas teias locais da política e do mercado em que o espaço da autonomia subjetiva era articulado. Na casa, então, realizava-se uma dinâmica constante de integração e disjunção (DOUGLAS, 1991); uma relação porosa entre os espaços familiares dos apartamentos e os espaços públicos e econômicos do político.

\section{Referências}

ARRETCHE, Marta. Trajetórias das desigualdades: como o Brasil mudou nos últimos cinquenta anos. São Paulo: Editora Unesp; CEM, 2015.

BACHELARD, Gaston. The poetics of space. Boston: Beacon Press Books, 1958.

BARTELT, Dawid Danilo. A “nova classe média” no Brasil como conceito e projeto político. Rio de Janeiro: Fundação Heinrich Böll, 2013.

BOURDIEU, Pierre. Distinction: a social critique of the judgment oft taste. Cambridge: Harvard University Press, 1984.

CHAUÍ, Marilena. "Uma nova classe trabalhadora." In: Lula e Dilma: dez anos de governos pós-neoliberais no Brasil. São Paulo: Boitempo, 2013, p.123-134.

COLLINS, Daryl; MORDUCH, Jonathan; RUTHERFORD,Stuart; RUTHVEN, Orlanda (Eds.). Portfolios of the poor: how the world's poor live on \$2 a day. Princeton; Oxford: Princeton University Press, 2009.

DOUGLAS, Mary. “The idea of a home: A kind of space". Social Research, 58 (1) ed, p. 287-307, 1991.

FERGUSON, James. "Power topographies" In: VINCENT, J; NUJENT, D. A companion to the anthropology of politics. Oxford; Malden; Victoria: Blackwell Publishing, p. 382-399, 2004.

2015 .

Give a man a fish: reflections on the new politics of distribution. Durham; London: Duke University Press,

HAN, Clara. "Symptoms of another life: time, possibility, and domestic relations in Chile's credit economy". Cultural Anthropology, Ed. 26(1), p. 7-32, 2011.

HIRSCHMAN, Albert O. Exit, voice, and loyalty: responses to decline in firms, organizations and States. Cambridge; London: Harvard University Press, 1970.

KOPPER, Moisés. "La invención de la nueva clase media brasileña: de la antropología de los números a las políticas de movilidad social”. In: ADAMOVSKY, E; VISACOVSKY, S; VARGAS, P. (Ed.). Clases medias: novos enfoques desde la sociología, la historia y la antropología. Buenos Aires: Ariel, 2014.

"Designing Brazil's new middle class: economic science and welfare policies in the making of a social category." Urbanities, 5(2), p. 20-31, 2015a.

"Vestígios de um 'novo Brasil': a configuração do mercado de pesquisas para a 'base da pirâmide.". In: YACCOUB, H. Consumo Popular no Brasil: contribuições da antropologia e sociologia. Rio de Janeiro: Mundo do Marketing, 2015b, p. 63-98.

Arquiteturas da esperança: uma etnografia da mobilidade econômica no Brasil contemporâneo." Rio Grande do Sul: Universidade Federal do Rio Grande do Sul (UFRGS), 2016a. 
““Minha casa, minha vida': experts, sentidos de classe e a invenção do 'mercado' da casa própria no Brasil contemporâneo." Horizontes Antropológicos, 45 (22), p.185-215, 2016 b.

.; Damo, Arlei Sander. 2018. “A Emergência e Evanescência da Nova Classe Média Brasileira”. Horizontes Antropológicos, 50, pp. 335-376.

LARKIN, Brian. "The Politics and Poetics of Infrastructure.” Annual Review of Anthropology, 42 (September), 2013.

LIVINGSTON, Julie. "Suicide, risk, and investment in the heart of the African Miracle”. Cultural Anthropology, 24(4), p. 652-80, 2009.

MORDUCH, Jonathan; SCHNEIDER, Rachel. The financial diaries: how american families cope in a world of uncertainty. Princeton: Princeton University Press, 2017.

MÜLLER, Lúcia. "Negotiating debts and gifts: financialization policies and the economic experiences of low-income social groups in Brazil”, Vibrant 11(1), p. 191-221, 2014.

MURPHY, Edward. "Life in debt: times of care and violence in neoliberal Chile". American Anthropologist, 116(1), 2014

NERI, Marcelo Cortes. A nova classe média: o lado brilhante dos pobres. Rio de Janeiro: CPS/FGV. Disponível em: < http://www.cps.fgv.br/ibrecps/ncm2010/NCM_Pesquisa_FORMATADA.pdf>. Acesso em: 10/02/ 2017. OSSANDÓN, José; ARIZTÍA, Tomás; BARROS, Macarena; PERALTA, Camila. "Dossiê: finanças e sociedade contabilidad en los márgenes accounting in the margin.” Civitas,17(1), p.1-26, 2017.

Paes de Barros, Ricardo, Miguel Nathan Foguel, and Gabriel Ulyssea. Desigualdade de renda no Brasil: uma análise da queda recente. Brasília: IPEA, 2017.

POCHMANN, Marcio. Nova classe média? o trabalho na base da pirâmide social brasileira. São Paulo: Boitempo, 2012.

O mito da grande classe média: capitalismo e estrutura social. São Paulo: Boitempo, 2014. SALATA, André. “Notas Sobre a Tese Da Nova Classe Média Brasileira.” Observatório Das Metrópoles, 2013. Salata, André. A classe média brasileira: posição social e identidade de classe. Rio de Janeiro: Letra Capital, 2016.

SCALON, Celi. “Desigualdade, pobreza e políticas públicas: notas para um debate.” Contemporânea, 1, p.49-68, 2011.

; SALATA, André. "Uma nova classe média no Brasil da última década? o debate a partir da perspectiva sociológica”. Revista Sociedade e Estado, 27(2), p. 387- 407, 2012.

SOUSA, Amaury de; LAMOUNIER, Bolivar. A classe média brasileira: ambições, valores e projetos de sociedade. Rio de Janeiro; Brasília: Elsevier; Confederação Nacional da Indústria, 2010.

SOUZA, Jessé. 2010. Os batalhadores brasileiros: nova classe média ou nova classe trabalhadora? 2nd ed. Belo Horizonte: Editora UFMG, 2010.

VATIN, François. Évaluer et Valoriser: une sociologie économique de la mesure. Paris: Presses Universitaires du Mirail, 2013.

WEIGEL, Sigrid. “On the 'Topographical Turn': Concepts of Space in Cultural Studies and Kulturwissenschaften. A Cartographic Feud.” European Review, 17(1), p.187- 201, 2009.

Wilkis, Ariel. Las sospechas del dinero: moral y economía en la vida popular. Buenos Aires: Paidós, 2013. XAVIER SOBRINHO, Guilherme G.de F. “A 'classe C’ e sua alardeada ascensão: nova? classe? média?” Indicadores Econômicos FEE 38(4), p. 67- 80, 2011.

YACCOUB, Hilaine. "Lições da favela: as economias de compartilhamento de bens e serviços na barreira do Vasco/ RJ." Universidade Federal Fluminense, 2015. 
ZELIZER, Viviana A. The social meaning of money: pin money, paychecks, poor relief, and other currencies. Princeton: Princeton University Press, 1994.

“Circuits Within Capitalism.pdf.” In: NEE, V; SWEDBERG. The Economic Sociology of Capitalism. Princeton: Princeton University Press, 2005a.

The Purchase of Intimacy. Princeton: Princeton University Press, 2005b.

2011. Economic Lives: How Culture Shapes the Economy. Princeton: Princeton University Press, 2011.

Recebido em: 16/01/2018

Aceito em: 31/03/2018 